\title{
Commentary: Evaluating the Migration Mortality Hypothesis Using Monarch Tagging Data
}

\author{
James A. Fordyce ${ }^{1 *}$, Chris C. Nice ${ }^{2}$ and Matthew L. Forister ${ }^{3}$ \\ ${ }^{1}$ Department of Ecology and Evolutionary Biology, University of Tennessee, Knoxville, Knoxville, TN, United States, \\ ${ }^{2}$ Department of Biology, Population and Conservation Biology, Texas State University, San Marcos, TX, United States, \\ ${ }^{3}$ Department of Biology, University of Nevada, Reno, NV, United States
}

Keywords: monarch butterfly (Danaus plexippus), migration, milkweed, tagging, recovery rate, monarch decline, power

\section{A Commentary on}

Evaluating the Migration Mortality Hypothesis Using Monarch Tagging Data

by Taylor, O. R. Jr., Pleasants, J. M., Grundel, R., Pecoraro, S. D., Lovett, J. P., and Ryan, A. (2020). Front. Ecol. Evol. 8:264. doi: 10.3389/fevo.2020.00264

OPEN ACCESS

Edited by:

David Jack Coates,

Conservation and Attractions

(DBCA), Australia

Reviewed by:

Ryan Norris,

Nature Conservancy of

Canada, Canada

*Correspondence:

James A. Fordyce

jfordyce@utk.edu

Specialty section:

This article was submitted to

Conservation and Restoration

Ecology,

a section of the journa

Frontiers in Ecology and Evolution

Received: 10 September 2020

Accepted: 11 November 2020

Published: 30 November 2020

Citation:

Fordyce JA, Nice CC and Forister ML (2020) Commentary: Evaluating the Migration Mortality Hypothesis Using Monarch Tagging Data.

Front. Ecol. Evol. 8:604914. doi: 10.3389/fevo.2020.604914
Recent reports of declining insects have sparked widespread public interest and close examination of long-term datasets. The reported changes in insect abundance and diversity often involve species with poorly understood life histories. Against this backdrop, the monarch butterfly plays a unique role, not only because of familiarity to the public and declining abundance in North American (Espeset et al., 2016; Pelton et al., 2019), but also because of its relatively well-understood natural history. Thus, details of the monarch decline matter: unlike many insects, it is a species for which we might hope to identify causes of decline. It is in this spirit that we offer a reconsideration of the data presented by Taylor et al. (2020) who tested hypotheses pertaining to eastern monarch population decline.

A puzzle has been that the overwintering monarch population in Mexico has been declining while some reports from the eastern breeding grounds have failed to detect corresponding declines in summer count numbers (e.g., Badgett and Davis, 2015). Inamine et al. (2016) found successive positive relationships between adult numbers at different stages during the northward migration, but not between the last summer generation and the overwintering colony size. Thus, the possibility was raised that the fall migration to Mexico and overwintering period might be a weak link in the migratory life cycle, which would, in turn, suggest conservation attention should not be focused too narrowly on summer milkweed resources.

Taylor et al. (2020) present new tagging data, concluding that none of the expectations of the migration mortality hypothesis are supported. They conclude the following: (1) the apparent disconnect between late summer and overwintering numbers reflects poor summer data used in previous analyses, (2) the recovery rate (equated with migration success) of tagged monarchs is not correlated with overwintering numbers, and (3) recovery rate has not decreased over time. We address each of these conclusions in turn.

Contrary to previous analyses using adult counts from different sources (Inamine et al., 2016), Taylor et al. find that the number of tagged individuals in the Midwest explains $74 \%$ of annual variation in overwintering hectares in Mexico. However, the strength of this association is influenced by the fact that year was not included in the model. Variance partitioning shows that roughly half of the $74 \%$ of explained variation is, in fact, shared with year (all re-analyses in Supplementary Material). Thus, the high correlation between tagged individuals 
and overwintering colony size exists, in part, because of the overall decline of the eastern monarch population. We recognize that this indeed advances our understanding of the eastern monarch, as summer densities were not previously seen as part of the overall decline.

Next, Taylor et al. examine the relationship between recovery rate and overwintering population size, concluding that no significant relationship exists. They test a regression model where recovery rate is predicted by year and find that year is not significant. From that result, they accept the null of no change over time in recovery rate, from which they conclude that the fall migration to Mexico is not a concern. These models, depending on the subset of data analyzed, have low power (between 0.21 and 0.25 at $\alpha=0.05$ ). Thus, failure to reject the null should not be considered evidence supporting the null. In short, they do not have sufficient statistical power to conclude that recovery rate has not changed over time.

We also consider a complementary model not considered by Taylor et al.: we include both year and overwintering colony size in the same model predicting recovery rate. This model allows us to ask if recovery rate has changed while controlling for population size (measured by colony size). In this model, year does indeed become a predictor of interest (Figure 1). Year has a positive coefficient across this and other models, including a "non-significant" model where it is the only predictor for recovery rate (standardized slope $\pm \mathrm{SE}=0.31 \pm 0.26$ ). Thus, recovery rate appears to be increasing through time. Based on the premise of Taylor et al.'s argument, migration success has apparently increased over time. While this seems unlikely, it does raise other considerations.
We propose two explanations for the apparent increase in recovery rate. Increasing recovery rate might reflect increasing effort expended recovering tags. Search effort in Mexico has not been quantified, and thus search effort cannot be accounted for when examining recovery rate. The lack of information on search effort compromises the utility of these data to model migration success. Second, it could be that more monarchs are dying upon reaching Mexico and, thus, it is easier to find dead individuals on the forest floor. Neither of these possibilities can be addressed without quantification of search effort in Mexico. Regardless, the unquantified search effort combined with the low power of the models creates uncertainty about Taylor et al.'s conclusion that "all is well" during the fall migration to Mexico. Moreover, even if effort was quantified, there would be the problem of death in Mexico as a result of stress accumulated during the southward flight as opposed to less favorable overwintering conditions (Barve et al., 2012). That problem further calls into doubt the extent that these data can address the "migration limitation hypothesis."

Finally, the two central hypotheses outlined by Taylor et al. (involving resources in the breeding grounds vs. the migration to Mexico) are not mutually exclusive. Would anyone be surprised if monarchs are being negatively affected by factors at many or all points of their annual cycle? The debate posited by Taylor et al. of "milkweed limitation hypothesis" vs. "migration limitation hypothesis" suggests a false dichotomy and does not address important data gaps. We suggest that methods for quantification of search effort in Mexico be considered. For example, perhaps the number of individuals and their effort (e.g., hours spent searching) turning in tagged butterflies could be quantified and reported. We hope the points raised here add to the discussion of the monarch butterfly, possibly the most iconic representative of insect declines.
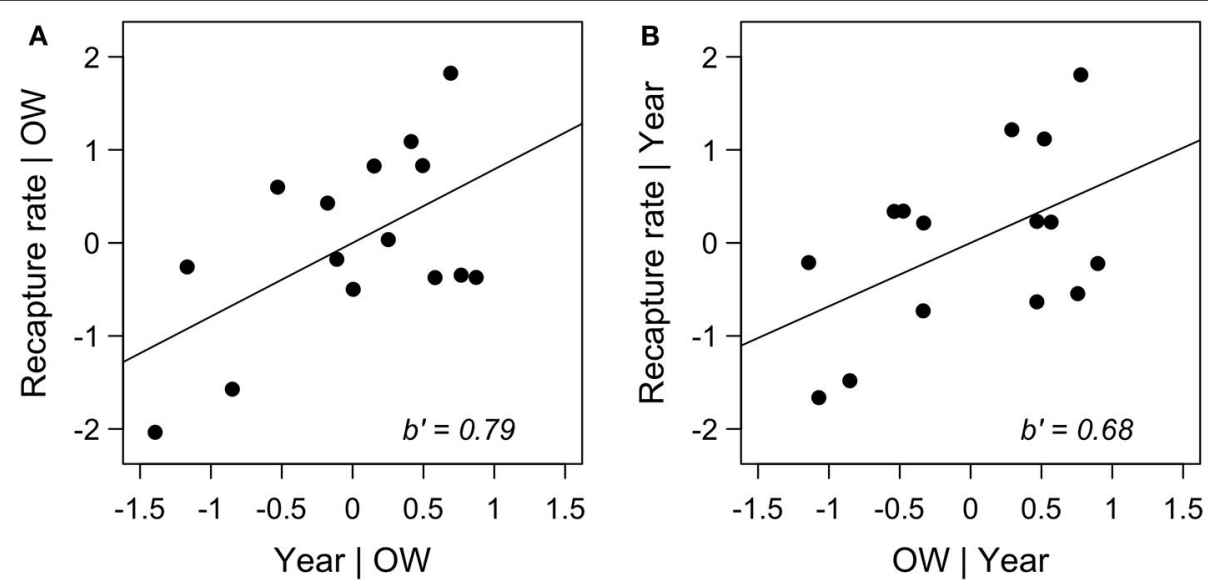

FIGURE 1 | Partial regression plots for a model where total recapture rate is predicted by year and over-wintering colony size (OW). The left panel (A) shows the relationship between recapture rate and year while controlling for over-wintering colony size $\left(F_{1,12}=5.60, p<0.05\right.$; standardized slope $\left.\pm \mathrm{SE}=0.79 \pm 0.33\right)$, while the right panel $\mathbf{( B )}$ is the relationship between recapture rate and $\mathrm{OW}$ while controlling for year $\left(F_{1,12}=4.16, p=0.06\right.$; standardized slope $\left.\pm \mathrm{SE}=0.68 \pm 0.33\right)$. Data were standardized for ease of comparison. Failure to detect an effect of over-wintering colony size at $\alpha=0.05$ is most likely due to overall low power of the model (power $=0.56$ ). A positive coefficient for the effect of year was also present in models restricted to Midwest or Northeast data. 


\section{AUTHOR CONTRIBUTIONS}

JF, CN, and MF conceived the commentary, analyzed the data, and wrote the manuscript. All authors contributed to the article and approved the submitted version.

\section{REFERENCES}

Badgett, G., and Davis, A. K. (2015). Population trends of monarchs at a northern monitoring site: analyses of 19 years of fall migration counts at Peninsula Point, MI. Ann. Entomol. Soc. Am. 108, 700-706. doi: 10.1093/aesa/sav060

Barve, N., Bonilla, A. J., Brandes, J., Brown, J. C., Brunsell, N., Cochran, F. V., et al. (2012). Climate-change and mass mortality events in overwintering monarch butterflies. Rev. Mex. Biodivers. 83, 817-824. doi: 10.7550/rmb.26460

Espeset, A. E., Harrison, J. G., Shapiro, A. M., Nice, C. C., Thorne, J. H., Waetjen, D. P., et al. (2016). Understanding a migratory species in a changing world: climatic effects and demographic declines in the western monarch revealed by four decades of intensive monitoring. Oecologia 181, 819-830. doi: 10.1007/s00442-016-3600-y

Inamine, H., Ellner, S. P., Springer, J. P., and Agrawal, A. A. (2016). Linking the continental migratory cycle of the monarch butterfly to understand its population decline. Oikos 125, 1081-1091. doi: 10.1111/oik.03196

Pelton, E. M., Schultz, C. B., Jepsen, S. J., Black, S. H., and Crone, E. E. (2019). Western monarch population plummets: status, probable

\section{SUPPLEMENTARY MATERIAL}

The Supplementary Material for this article can be found online at: https://www.frontiersin.org/articles/10.3389/fevo. 2020.604914/full\#supplementary-material

causes, and recommended conservation actions. Front. Ecol. Evol. 7:258. doi: $10.3389 /$ fevo.2019.00258

Taylor, O. R. Jr., Pleasants, J. M., Grundel, R., Pecoraro, S. D., Lovett, J. P., and Ryan, A. (2020). Evaluating the migration mortality hypothesis using monarch tagging data. Front. Ecol. Evol. 8:264. doi: 10.3389/fevo.2020. 00264

Conflict of Interest: The authors declare that the research was conducted in the absence of any commercial or financial relationships that could be construed as a potential conflict of interest.

Copyright (c) 2020 Fordyce, Nice and Forister. This is an open-access article distributed under the terms of the Creative Commons Attribution License (CC BY). The use, distribution or reproduction in other forums is permitted, provided the original author(s) and the copyright owner(s) are credited and that the original publication in this journal is cited, in accordance with accepted academic practice. No use, distribution or reproduction is permitted which does not comply with these terms. 